\title{
SOBRE A POSSIBILIDADE DE UMA PEDAGOGIA CRÍTICA PARA A ESCOLA PÚBLICA CONTEMPORÂNEA
}

\author{
SOBRE LA POSIBILIDAD DE UNA PEDAGOGÍA CRÍTICA PARA LA ESCUELA \\ PÚBLICA CONTEMPORÁNEA
}

\author{
ON THE POSSIBILITY OF A CRITICAL PEDAGOGY FOR CONTEMPORARY \\ PUBLIC SCHOOL
}

\author{
Michel LINS ${ }^{1}$ \\ José Luis DERISSO ${ }^{2}$ \\ Edemir Jose PULITA ${ }^{3}$
}

RESUMO: O artigo toma como ponto de partida teorias críticas - particularmente as elaboradas por sociólogos franceses na década de 1970 - que concebem a escola pública na sociedade burguesa como essencialmente reprodutora da ideologia e das relações sociais capitalistas. Com o objetivo de sustentar que tais críticas não levam em conta o caráter histórico e dialético da instituição escolar ao não enxergar suas contradições, tornando-se, assim, unilateral, esse artigo se propõe a fazer o contraponto a partir dos fundamentos teóricometodológicos da Pedagogia Histórico-Crítica idealizada por Demerval Saviani, no que diz respeito à concepção de formação humana presente na tradição marxista e do caráter contraditório da escola pública na sociedade de classes. Autores como Marx, Engels, Gramsci e György Márkus são utilizados para sustentar tais fundamentos

PALAVRAS-CHAVE: Teorias crítico-reprodutivistas da educação. Pedagogia históricocrítica. Formação humana. Educação escolar.

RESUMEN: El artículo toma como punto de partida las teorías críticas -en particular las desarrolladas por los sociólogos franceses en los años 70- que conciben la escuela pública en la sociedad burguesa como reproductora esencial de la ideología y de las relaciones sociales capitalistas. Para argumentar que dicha crítica no tiene en cuenta el carácter histórico y dialéctico de la institución escolar al no ver sus contradicciones, convirtiéndose así en unilateral, este artículo pretende hacer un contrapunto desde los fundamentos teóricos y metodológicos de la Pedagogía Histórica Crítica idealizada por Demerval Saviani, respecto a la concepción de la formación humana presente en la tradición marxista y el carácter contradictorio de la escuela pública en la sociedad de clases. Autores como Marx, Engels, Gramsci y György Márkus sirven de apoyo a estos fundamentos

\footnotetext{
${ }^{1}$ Universidade Estadual do Oeste do Paraná (UNIOESTE), Cascavel - PR - Brasil. Mestrando no Programa de Pós-Graduação em Educação. ORCID: https://orcid.org/0000-0002-6940-4236. E-mail: mixelzera@gmail.com ${ }^{2}$ Universidade Estadual do Oeste do Paraná (UNIOESTE), Cascavel - PR - Brasil. Professor no Colegiado de Pedagogia e no Programa de Pós-Graduação em Educação. Doutorado em Educação Escolar (UNESP). ORCID: https://orcid.org/0000-0003-4044-4493. E-mail: E-mail: joseluisderisso@yahoo.com.br

${ }^{3}$ Universidade Estadual do Oeste do Paraná (UNIOESTE), Cascavel - PR - Brasil. Professor Colaborador. Doutorado em Educação (UNB). ORCID: https://orcid.org/0000-0002-2834-2331. E-mail: edemirjose@hotmail.com
} 
PALABRAS CLAVE: Teorías crítico-reproductivas de la educación. Pedagogía histórica crítica. Formación humana. Educación escolar.

ABSTRACT: The article takes as a starting point critical theories - particularly those developed by French sociologists in the 1970s - that conceive the public school in bourgeois society as essentially reproducing ideology and capitalist social relations. In order to argue that such criticism does not take into account the historical and dialectical character of the school institution by not seeing its contradictions, thus becoming unilateral, this article aims to make a counterpoint from the theoretical and methodological foundations of Critical Historical Pedagogy idealized by Demerval Saviani, with respect to the conception of human formation present in the Marxist tradition and the contradictory character of public school in class society. Authors such as Marx, Engels, Gramsci, and György Márkus are used to support such foundations

KEYWORDS: Critical-reproductive theories of education. Critical-historical pedagogy. Human formation. School education.

\section{Introdução}

Na história da educação, encontramos extremos no entendimento das possibilidades da escola contemporânea, que vão desde tomá-la como instrumento de manutenção da ordem social vigente (ALTHUSSER, 1974; 1983; 1985; BOURDIEU, 1974) até a crença de que a mesma possa operar transformações na sociedade, como se não fossem socialmente determinadas. Este seria o caso, segundo Saviani (2013), tanto da pedagogia tradicional como da pedagogia nova.

No contexto do pensamento iluminista, havia um anseio muito honesto de que, por meio do progresso no conhecimento, a humanidade romperia os limites impostos pela natureza. A razão era tida como o instrumento privilegiado para a construção de um mundo livre dos preconceitos que atravancavam o desenvolvimento das ciências e alimentavam a desarmonia social. Lembrando que no contexto do Antigo Regime, os Estados europeus eram, via de regra, governados por monarquias absolutas, legitimadas por uma suposta origem divina que garantia, de certo modo, o equilíbrio político entre as duas ordens privilegiadas (nobreza e clero) e o chamado terceiro estado (burguesia).

No processo da Revolução Francesa, iniciada em 1789, a escola estatal é criada e seus currículos estruturados a partir da perspectiva de disseminação do conhecimento, sobretudo científico. Porém, um conjunto de fatores frustram este projeto, acabando por impor um modelo de educação excludente que garantia acesso ao conhecimento superior, mais elaborado, apenas a uma minoria de crianças e jovens provindos das classes abastadas, ao 
passo que aos filhos dos trabalhadores, o acesso possível era por meio de uma educação rebaixada e destinada à responder às necessidades do capital, sobretudo, à formação de mão de obra para a indústria, evidenciando assim a distinção feita por Manacorda (2010), em sua obra "História da Educação: da antiguidade até os dias atuais", entre aculturação e aprendizado, segundo a qual:

Aculturação quer dizer socialização, inserção de cada adolescente no conjunto vivo da sociedade adulta; aprendizado quer dizer relação com o trabalho e com todo o desenvolvimento, não somente das forças produtivas, mas também das relações sociais nas quais elas se inserem (p. 17).

Entre os fatores deste desvio de propósitos da instituição escolar temos a intensificação da divisão social do trabalho, com a decorrente especialização e fragmentação do conhecimento elaborado, e a entrada do proletariado na cena política europeia, sobretudo no contexto das revoluções burguesas de 1848. Nesse novo contexto, a burguesia não mais necessita da revolução e muito menos do apoio das classes populares para exercer sua dominação, conforme necessitava no período precedente, para combater as ordens remanescentes da sociedade feudal, a nobreza e o clero. A classe burguesa, após cumprir seu papel histórico revolucionário, transforma-se em classe reacionária que constitui entrave para o desenvolvimento histórico (LUKÁCS, 1992).

Na passagem do século XIX para o XX, surgem, no interior do chamado Movimento Escola Nova, teorias pedagógicas extremamente otimistas com relação ao papel da escola no sentido de construir uma sociedade democrática e superar as flagrantes desigualdades existentes na nova sociedade industrial. A base para a construção da apregoada sociedade democrática e progressista deveria ser a formação de indivíduos autônomos, que sabem pensar por si. Porém, os objetos de ensino pautados nos conhecimentos superiores (sobretudo, os dados pela ciência, filosofia e arte) foram negligenciados em prol de um ensino baseado no interesse e na curiosidade dos alunos. O movimento chamado de escola nova ganha projeção no Brasil após a Revolução de Trinta do século XX, e passa constituir-se em orientação oficial durante a Era Vargas, particularmente, no Estado Novo (1937-1945), vindo a perder força na década 1960 .

O estabelecimento da Ditadura Militar impõe reformas educacionais - na educação básica e na educação superior - e a adoção de uma orientação tecnicista, que visava, segundo seus idealizadores, a formação de capital humano para o desenvolvimento da nação. Na escola básica esta orientação se traduziu, entre outras coisas, na criação de cursos profissionalizantes no antigo Ensino Colegial (correspondente ao atual Ensino Médio) e na supressão de 
disciplinas escolares como Filosofia, Sociologia e Psicologia, acentuando, assim, o processo de descaracterização do papel da instituição escolar.

A crítica à orientação educacional da Ditadura Militar alimentou-se das críticas à escola francesa (e num sentido mais amplo à escola capitalista), operada por sociólogos que ganharam grande projeção acadêmica no campo da sociologia da educação na década de 1970. As teorias decorrentes destas críticas foram denominadas por Dermeval Saviani de "teorias crítico-reproduvistas de educação", a partir do entendimento de que mesmo que, por um lado, contribuíssem para fortalecer a crítica à orientação que a classe dominante, por meio do Estado, impõe à educação pública no Brasil, por outro, eram estéreis no que diz respeito à instrumentalização da resistência no interior das escolas.

Com o objetivo de sustentar que as críticas à escola capitalista contemporânea que se desenvolveram no âmbito da sociologia, particularmente na França na década de 1970, são unilaterais na medida em que não levam em conta o caráter histórico e contraditório e de problematizar a possibilidade de existência de uma resistência efetiva por meio da pedagogia à orientação capitalista das escolas, estruturamos nossa exposição em dois momentos: primeiro, a crítica da escola capitalista a partir das teorias de Louis Althusser e Pierre Bourdieu e de autores brasileiros que de forma mais ou menos aproximada reproduzem esta crítica; segundo, a crítica de Dermeval Saviani a estas teorias e sua proposição pedagógica apoiada no materialismo histórico e dialético alicerçada na concepção antropológica marxista que aqui apresentamos de forma sintética a partir de György Márkus (2015).

A pesquisa que origina este artigo é essencialmente bibliográfica e teoricamente ancorada no materialismo histórico e dialético, que concebe a realidade como síntese de múltiplas determinações, e que recusa caminhos propostos por outras metodologias que vislumbram dicotomias, falsas do nosso ponto de vista, como sujeito/objeto, individual/social, particular/universal e quantidade/qualidade, entre outras, assim como a ilusão da possibilidade de neutralidade ou distanciamento total do sujeito do conhecimento em relação ao objeto a conhecer.

\section{As teorias crítico-reprodutivistas da educação e a crítica da escola capitalista no Brasil}

Para Althusser (1983), a escola capitalista se apresenta e se organiza de acordo com uma qualificação mínima por apresentar uma ideologia escolar, que é o 
ideológica burguesa, ou seja, a escola é um dos aparelhos ideológicos que constrói um pensamento único burguês, sendo incapaz de romper com a sociedade. Assim essa ideologia é material, sendo assim ela se materializa nas relações humanas da vida social (p. 81).

Em "Ideologia e Aparelhos Ideológicos do Estado", Althusser (1985) descreve e analisa os mecanismos de reprodução utilizados pela sociedade capitalista como um todo e na escola em particular. Para este autor, existe no Estado uma distinção entre dois tipos de aparelhos: os Aparelhos Repressivos de Estado (o governo, a administração, o exército, a polícia, os tribunais, as prisões etc.) e os Aparelhos Ideológicos de Estado (AIE), dentre os quais estão as igrejas, as escolas, a família, o jurídico, o político, o sindical, a imprensa e a cultura. "Como AIE dominante, vale dizer que escola constitui o instrumento mais acabado de reprodução das relações de produção de tipo capitalista" (SAVIANI, 2012, p. 23).

Para Althusser (1985), os professores são agentes, mesmo que inconscientes, de tal reprodução:

[...] e muitos (a maioria) não têm nem um princípio de suspeita do 'trabalho' que o sistema (que os ultrapassa e esmaga) os obriga a fazer, ou, o que é pior, põem todo seu empenho e engenhosidade em fazê-lo de acordo com a última orientação (os famosos métodos novos!). Eles questionam tão pouco, que contribuem, pelo seu devotamento mesmo, para manter e a alimentar esta representação ideológica da escola, que faz da Escola hoje algo tão 'natural' e indispensável, e benfazeja aos nossos contemporâneos como a Igreja era 'natural', indispensável e generosa para nossos ancestrais de séculos atrás (p. 80-81).

Seguindo este pensamento no que se refere à escola reprodutora da vida social capitalista por meio da cultura e, portanto, não revolucionária, Bourdieu (1974) também evidencia que a escola capitalista é pensada/projetada para perpetuar uma ordem social/conservação a partir do patrimônio cultural:

Transpondo-se para o caso das sociedades divididas em classes a representação da cultura e da transmissão cultural em geral aceita pelos etnólogos, tais teorias baseiam-se no postulado tácito de diferentes ações pedagógicas que operam em uma formação social, vale dizer, tanto aquelas que as famílias das diferentes classes sociais exercem, como a que a escola exerce, colaboram harmoniosamente na transmissão de um patrimônio cultural concebido como uma propriedade indivisa do conjunto de "sociedade" (p. 297).

Essa transposição da divisão social classista e das questões hierárquicas do patrimônio cultural apresentada por Bourdieu demonstra que o acesso ao conhecimento, no quadro das relações sociais capitalistas, é fragmentado e resulta numa organização que estratifica o 
sujeito. A passagem acima evidencia que a conservação social por intermédio da cultura acontece em uma relação entre famílias e escola, ou seja, o acesso à cultura limita a instrução do sujeito na medida em que este não consegue aceder o patrimônio cultural no convívio familiar e a escola também lhe nega esse acesso.

Bourdieu (1974) aponta que as relações de poder se constroem a partir de um conjunto de símbolos (crenças, conhecimentos, regras, cultura), dissimulando as forças de dominação e/ou reforçando a própria dominação - reproduzindo os valores sociais através da violência simbólica. Uma das consequências disso é que as vítimas (dentro e fora da escola) desconhecem a relação de dominação. $\mathrm{O}$ aluno, nesse caso, não percebe que a escola reforça e reproduz os modelos de desigualdade existentes na estrutura capitalista (BORDIEU, 1974).

Na mesma ótica de Bourdieu, Nogueira (2002) afirma que a escola legitima um poder que advém de três capitais fundamentais que se inter-relacionam: (i) o capital econômico ligado aos meios de produção e à renda (salário); (ii) o capital social: no conjunto de relações de que dispõe um indivíduo, sendo todo conhecimento acumulado na construção do habitus ${ }^{4}$, funcionando, de fato, na maioria das vezes, somente como meios auxiliares na acumulação de tal capital cultural; e (iii) o capital cultural: tudo o que passa a ser incorporado pelo agente. Nesse sentido, Nogueira (2002, p. 22) destaca:

[...] a importância de um componente específico do capital cultural, a informação sobre a estrutura e o funcionamento do sistema de ensino. Não se trata aqui apenas do conhecimento maior ou menor que se possa ter da organização formal do sistema escolar (ramos de ensino, cursos, estabelecimentos), mas, sobretudo, da compreensão que se tenha das hierarquias mais ou menos sutis que distinguem as ramificações escolares do ponto de vista de sua qualidade acadêmica, prestígio social e retorno financeiro.

Bourdieu (1974, p. 312-316) explicita que "as classes dominantes dispõem de um capital cultural muito mais importante que as demais classes, inclusive suas frações mais desfavorecidas em termos relativos". Segundo o autor, o que limita essa apropriação cultural limitação esta que a escola tende a reproduzir - é que "a maioria dos consumos culturais implica também no custo econômico, ou seja, a frequência ao teatro, não depende apenas do nível de instrução".

Com relação à reprodução da sociedade e à formação escolar conservadora, Althusser (1983) apresenta a escola enquanto uma matriz. Em seu campo, o sujeito é ideológico e, ainda, age pela ideologia. Nesta condição existem dois tipos de sujeitos: (i) o Sujeito que se

\footnotetext{
${ }^{4}$ Caracteriza-se pela "mediação entre as estruturas e a prática", ou seja, uma dialética entre estruturas sociais e mentais, formando a matriz geradora das práticas cotidianas (BOURDIEU, 2007, p. 296).
} 
apresenta com "S" maiúsculo. Este se faz Sujeito com conhecimento além do imediato e compreende como agir com a Teoria, apresentada com " $\mathrm{T}$ " maiúsculo por representar uma consciência capaz de entender as bases materiais/infraestruturais e assim interferir na realidade. Já o outro sujeito, é (ii) o sujeito apresentado com "s" minúsculo e seu conhecimento teórico também com " $\mathrm{t}$ " minúsculo. Tal sujeito que não compreende os fenômenos e não possui consciência da sua ideologia tende a se tornar subordinado tanto aos Sujeitos quanto a qualquer outro Aparelho Ideológico do Estado. Dessa forma, tal sujeito apenas descreve, reproduz e conserva, sem capacidade de compreender, transformar ou revolucionar a sociedade.

Para Althusser (1974 apud DORE, 2006, p. 332),

[...] a ideologia não tem história, constitui uma representação imaginária dos indivíduos com suas condições reais de existência, pois é uma distorção das relações reais; a ideologia tem uma existência material e interpela os indivíduos como sujeitos. Os aparelhos ideológicos do Estado, por meio de suas práticas e rituais, realizam as ideologias e, assim, contribuem para reproduzir as relações de produção: garantem a opressão de classe e suas condições de exploração e reprodução.

Nesse sentido, na qualidade de Aparelho Ideológico do Estado, a escola reproduz a ideologia burguesa com o fim de conservar a ordem social vigente. Por meio dos rituais escolares, reproduz uma disciplina de conservação do Estado burguês. Para romper com tal mecanismo de dominação é imprescindível o desenvolvimento de uma consciência revolucionária que possibilite a transformação do proletariado em "Sujeito" à altura de assumir o poder de Estado, substituir o aparelho de Estado repressivo por outro (proletário) e, em fases subsequentes, destruir completamente este mesmo Estado (ALTHUSSER, 1974).

Bourdieu (1974), por sua vez, vislumbra um processo de dominação na sociedade que se opera no plano da cultura, e nesse sentido guarda pequenas semelhanças com Althusser. Indica o autor que diferentes Aparelhos de Reprodução Simbólicas - ARS reproduzem no cotidiano as violências simbólicas. Nesse contexto, a escola reproduz a própria sociedade classista, forma indivíduos para dar continuidade à cultura dominante, manipula os conteúdos de acordo com os interesses trazidos pelos agentes superiores do sistema escolar, reproduz e distribui cultura de acordo com as diferentes posições sociais, aplica sanções e legitima as diferenças, a ordem e a dominação, desempenhando, então, a função de um aparelho de reprodução simbólica.

A denúncia bourdieusiana aponta para um processo de formação humana desigual, determinado pela apropriação desigual da cultura, que reforça as violências simbólicas e a 
hierarquia social. Tal escola influencia diretamente no êxito (ou não êxito) do indivíduo, na medida em que seu sucesso passa a ser determinado pela sua adaptação ao conjunto de regras impostas ao bem da manutenção estrutural da sociedade capitalista. Um dos fatores que concorreria para a reprodução é a desvinculação dos alunos de sua cultura original. Sobre isso, Nogueira (2002, p. 29-30), afirma que:

Para Bourdieu, esse domínio variaria de acordo com a maior ou menor distância existente entre o arbitrário cultural apresentado pela escola como cultura legítima e a cultura familiar de origem dos alunos. Para os alunos das classes dominantes, a cultura escolar seria a sua própria cultura, reelaborada e sistematizada. Para os demais, seria uma cultura 'estrangeira'.

Seria esse o motivo para o distanciamento entre a realidade escolar e os alunos das escolas públicas. Nesse sentido, a sociedade tende a reproduzir-se, na medida que as classes hegemônicas mantêm a soberania cultural e, por meio da dominação do Capital Cultural, produzem formas de violências simbólicas que, por sua vez, atuam como conservadoras dos status quo econômico e social.

A formação capitalista, para a linha crítica que abordamos no presente tópico, é fragmentada e fragmenta a possibilidade de humanização, para o que corrobora a escola burguesa que "visa a preparação de homens parciais, que serão rapidamente treinados no processo produtivo". Nessa perspectiva,

Professores e alunos não precisam saber muito sobre ciência e tecnologia. $\mathrm{O}$ capital concentra esse saber. $\mathrm{O}$ saber das sociedades modernas está pulverizado pelos cientistas parcelares (especialistas), pelos trabalhadores parcelares, pelos institutos e laboratórios de pesquisa especializados e distribuídos nos diversos recantos do mundo. O capital concentra e monopoliza a totalidade do saber e cada vez mais o condiciona à produção de mercadorias em escala internacional (SÁ, 1986, p. 28).

Nesses termos não teria como a escola não ser reprodutora e conservadora da ordem social.

Outro aspecto destacado pela crítica da escola capitalista é a dualidade educacional que se articula com a lógica da reprodução da divisão da sociedade em classes sociais, que impede o acesso do saber de forma equitativa para alunos de diferentes classes, permitindo para uns o acesso a "saberes básicos para a sua subsistência" e, a outros, um preparo "para galgar altos postos em campos de conhecimentos específicos", possibilitando ainda que alguns sejam "preparados para uma boa retórica" enquanto que outros sejam "direcionados a cumprirem funções específicas, inclusive como futuros agentes de repressão (FERRARO, 2014, p. 14). 
Outro traço característico da escola capitalista, segundo a crítica, é a defesa da meritocracia e do empreendedorismo. Sua lógica seria a mesma da lógica capitalista do livre mercado, segundo a qual a competição pela melhor formação possível é que garantirá, aos mais esforçados, os melhores postos de trabalho e o consequente sucesso financeiro. No plano escolar, tal lógica induz à classificação dos alunos a partir de seus próprios méritos, independente de contextos e histórias.

Outro aspecto ainda diz respeito à homogeneização da educação que, para Daiyrell (1996), constitui uma falácia capitalista. Segundo o autor, tal ideal de homogeneização e universalização da educação escolar retira desta instituição social a responsabilidade sobre o resultado da ação educativa. Argumenta ainda que se a escola é universal, todos devem buscar assimilar e apropriar o conhecimento descrito pelos professores, pressupondo um grau de igualdade social, individual, econômica e psicológica. Sendo assim, os alunos tornam-se "coisas", cuja diversidade real fica "reduzida a diferenças apreendidas na ótica da cognição (bom ou mau aluno, esforçado ou preguiçoso etc.) ou sob o ponto de vista do comportamento (bom ou mau aluno, obediente ou rebelde, disciplinado ou indisciplinado etc.)" (DAYRELL, 1996, p. 5). Nesse caso, a escola desconsidera as dimensões humanas individuais e impede uma visão de totalidade da formação humana e do próprio ser humano (DAYRELL, 1996).

Assim, a educação escolar capitalista busca, segundo a crítica, criar no aluno uma internalização que legitima a hierarquia social, transformando-o em agente ativo e passivo: ativo na reprodução social e em pequenas mudanças estruturais, e passivo para com a possibilidade de uma luta transformadora, o que converte esta mesma educação em instrumento de reprodução social orientada pela classe dominante. A força reprodutora da educação escolar constitui-se, então, numa violência que não precisa ser aplicada diretamente ao corpo. Trata-se, geralmente, de violência simbólica, na qual a legitimação do poder se faz por meio de estruturas que dominam e subordinam seus elementos. No caso da escola, essa violência está vinculada às relações de poder estruturais da própria escola e o poder sobre ela aplicado na figura classista de dominação, incorporada na figura do Estado.

Zarakin (2001), baseando-se em Bourdieu e Passeron, afirma que a educação representa um instrumento histórico essencial para a continuidade, pois sustenta o monopólio da produção do capital simbólico "legítimo", o que permite assegurar a legitimação da sua dominação através da violência simbólica.

A concepção da escola reprodutora - quer da ideologia quer das relações de desigualdade social - nega em maior ou menor grau, a depender do autor, a possibilidade de 
uma ação pedagógica contra hegemônica nos marcos da instituição escolar e dos sistemas educacionais. Tal concepção é criticada por Demerval Saviani, conforme o tópico que segue.

\section{Formação humana e possibilidades da educação escolar}

Pensar a formação humana e, consequentemente, a educação é uma tarefa inócua sem se levar em consideração a formação da humanidade de forma concreta e historicamente dada. Como premissa desta reflexão, trazemos as ideias de Dermeval Saviani $(2005,2007)$ acerca da natureza e especificidade da educação que se expressa de forma emblemática nesta passagem: "[...] o trabalho educativo é o ato de produzir, direta e intencionalmente, em cada indivíduo singular, a humanidade que é produzida histórica e coletivamente pelo conjunto dos homens." (SAVIANI, 2005, p. 13).

Nessas relações, Saviani (2005, p. 22) defende que:

[...] a compreensão da natureza da educação enquanto um trabalho nãomaterial, cujo produto não se separa do ato de produção, permite-nos situar a especificidade da educação como referida aos conhecimentos, ideias, conceitos, valores, atitudes e hábitos, símbolos sob o aspecto de elementos necessários à formação da humanidade em cada indivíduo singular, na forma de uma segunda natureza, que se produz, deliberada e intencionalmente, através de relações pedagógicas historicamente determinadas que se travam entre os homens.

A partir desse pressuposto, o autor indica que a pedagogia deve "preocupar-se com a identificação dos elementos naturais e culturais necessários à constituição da humanidade em cada ser humano e à descoberta das formas adequadas para se atingir esse objetivo" (SAVIANI, 2005, p. 22).

Em alusão ao dualismo educacional, segundo o autor, os antagonismos da sociedade de classes tendem a impor diversos obstáculos para uma educação transformadora, uma vez que "a impossibilidade da universalização efetiva da escola, a impossibilidade do acesso de todos ao saber, a impossibilidade de uma educação unificada [...] leva a se propor um tipo de educação para uma classe e outro tipo para outra classe" (SAVIANI, 2007, p. 18). Dessa reflexão, o autor conclui que "o desenvolvimento da educação e, especificamente, da escola pública entra em contradição com as exigências inerentes à sociedade de classes de tipo capitalista” (SAVIANI, 2007, p. 20). 
A concepção de educação de Saviani (2007) e sua proposição de uma Pedagogia Histórico-Crítica se assentam, como toda pedagogia, numa determinada concepção de formação do indivíduo. Corrobora para esta concepção os estudos de György Márkus (2015), expostos na obra "Marxismo e antropologia: o conceito de 'essência humana' na filosofia de Marx", para quem a essência humana constitui "um conjunto de relações sociais existentes, não só nos contatos pessoais efêmeros entre os indivíduos, mas também nos sistemas de produção objetivados, costumes, linguagem, instituições e culturas" (MÁRKUS, 2015, p. 17). Nestes termos, a formação do ser humano ocorre nas inter-relações da história com a vida social. Do que apreendemos que a escola seria uma das instituições envolvidas nesta formação, com uma natureza e especificidade próprias, conforme visto anteriormente, neste artigo.

Tal concepção de essência humana remete à questão da especificidade do Homem $^{5}$ que, portanto, não pode ser aplicada a outras espécies animais. Este Homem é parte integrante da natureza, porém, não resulta apenas do processo de formação biológica, mas, e sobretudo, do "desenvolvimento sócio-histórico do homem” (MÁRKUS, 2015, p. 22). Nesta perspectiva, o homem se forma ontologicamente pela história, e se constrói por meio do trabalho. Trabalho este que não tem o sentido de mero esforço, conforme nos é dado pelo senso comum que tende a igualar a atividade vital de todos os seres vivos - e que comumente é exemplificada pela atividade da aranha, da formiga, da abelha ou do castor - mas se constitui na realidade daquela atividade que "torna seus objetos apropriados para uso humano" (MÁRKUS, 2015, p. 22), atividade esta que possui planejamento, intencionalidade e propósito, conforme apreendemos da passagem que segue:

$\mathrm{Na}$ atividade do trabalho seu produto desenha-se na mente do trabalhador antes mesmo que a ação se efetive. É como se a atividade se realizasse duas vezes, uma em projeto e outra na ação efetiva. Isto significa dizer que o trabalho é uma atividade consciente e "teleológica", pois tem fim prédeterminado (DERISSO, 2012, p. 25).

Uma atividade que produz uma objetivação de vida e que permite contemplar um mundo criado pelo próprio homem, ou seja, o mundo da cultura. Uma objetivação que remete a um processo de produção e reprodução da cultura humana, a qual envolve tanto aspectos materiais como não-materiais, uma produção e reprodução da própria vida em sociedade (DUARTE, 2004).

${ }^{5}$ Grafamos Homem (com letra inicial maiúscula) para indica o ser social e homem (com letra inicial minúscula) para designar o ser biológico. 
O Homem aqui concebido é aquele que se apresenta numa condição sócio-histórica determinada, o que significa dizer que cada novo ser humano nasce em contexto de construções materiais e não-materiais pré-existentes, herança das gerações anteriores. Assim, a formação humana não se inicia do zero, pois parte sempre do patrimônio cultural da humanidade para integrar o processo dialético de apropriação e objetivação. Disto depreendese que a educação deva ser acessível a todos os indivíduos da espécie humana, e a escola, como espaço privilegiado de educação, deva garantir para as novas gerações os conhecimentos historicamente acumulados pela humanidade.

A partir da tese de Marx, segundo a qual a essência do homem se expressa no conjunto de relações sociais produzidas pelo conjunto dos homens, Márkus (2015) constata que a sociedade capitalista impede que esta essência se expresse indistintamente em todos os indivíduos, pois a sociedade capitalista retirou do homem as condições de se formarem pela verdadeira "Essência Humana", uma vez que a divisão do trabalho retira deste homem a consciência do significado da atividade do trabalho e produz um descompasso entre o desenvolvimento da consciência e da autoconsciência social. Do que decorre que a consciência se transforma em falsa consciência, porque negligencia o verdadeiro e essencial sentido de formação humana. Nesse sentido e pelas condições da vida social do homem, este passa a ser um sujeito alienado.

[...] o resultado da alienação é precisamente a 'essência humana' que é alienada e tirada do proletariado (no sentido de que o proletariado não pode realizá-la na própria vida), de modo que ela só pode ser recuperada através da transformação revolucionária da sociedade. [...] o trabalho alienado, aliena do homem seu próprio corpo, bem como a natureza fora dele, bem como a sua essência espiritual, a essência humana (MÁRKUS, 2015, p. 9091).

Indica Márkus (2015, p. 99) que “para Marx a 'essência humana' reside precisamente na 'essência' ou no ser do processo social global e evolutivo da humanidade, e na unidade interna desse processo". Assim, para entender a formação humana num sentido ontológico, faz-se necessário compreender onde e por que o homem deixa de se entender como sujeito social e passa a se ver como um indivíduo isolado com relação à atividade do trabalho, ao seu produto e às objetivações dele decorrentes, de modo que nesse processo de estranhamento, o indivíduo aliena-se com relação ao próprio gênero humano. O mundo social torna-se para este indivíduo tão exterior quanto o mundo natural, restando apenas a consciência da individualidade alienada. 
O processo de alienação na sociedade capitalista desenvolve-se a partir de alguns momentos. O primeiro momento é a alienação do indivíduo para com o produto do seu trabalho, levando a que o mesmo identifique o trabalho como uma atividade estranha e adversa e não mais como a atividade vital humana. Os momentos intermediários da alienação podem ser identificados na relação de estranhamento do indivíduo para com o processo de trabalho no qual se vê obrigado a inserir-se sem compreendê-lo e com o conhecimento técnico e científico, cuja identificação com o processo de trabalho também não é compreendido por este mesmo indivíduo. $\mathrm{O}$ momento culminante do processo de alienação é aquele no qual o indivíduo deixa de se identificar com o próprio gênero humano, por não entender sua especificidade de ser social (histórico-cultural). Nesta fase, o estranhamento se manifesta para com as expressões superiores do conhecimento humano (ciência, filosofia e arte) e também para com o conjunto das relações sociais, ou seja, com o produto do conhecimento e as formas de organização que a sociedade humana incorporou no processo histórico do qual o trabalho constitui o primeiro fato imaginável. A decorrência do processo de alienação a partir deste momento culminante é a falsa consciência de que a sociedade constitui um ambiente adverso no qual se deve sobreviver e que as regras de convívio social, a solidariedade, o respeito humano e a fraternidade são imposições externas a serem toleradas ou praticadas conforme a conveniência, tanto que o idealismo as apresenta como resultantes de contrato social celebrado por nossos ancestrais ou mesmo, às vezes os dois juntos, por força da religião (DERISSO; DUARTE, 2017, p. 13).

Sobre separar a formação humana da constituição da humanidade, Márkus (2015, p. 127), afirma que:

[...] compreender o conceito marxiano de 'essência humana', a ontologia marxiana do homem como ser histórico-social, não é uma simples 'explicação' particular do mundo, ou uma interpretação de vida social histórica, ela é enquanto teoria, uma concepção da parte de uma luta revolucionária pela transformação do 'mundo' e da sociedade, onde a liberdade e universalidade do homem é a parte da práxis revolucionária do proletariado.

Nossa abordagem sobre a formação humana parte das concepções de natureza e especificidade da educação de Saviani (2005; 2007), bem como do conceito de formação, valorizando a essência humana, conforme Márkus (2015). Ambas as abordagens pressupõem que a formação se dá a partir do trabalho enquanto elemento básico da humanização e da formação da cultura.

Entendendo que a escola deveria ser formadora (a partir) da essência humana, levando em consideração o caráter ontológico da formação humana, percebe-se uma incongruência com a proposta capitalista de escola, a qual aposta em uma formação estratificada, ou melhor, fracionada de indivíduo. A escola tipicamente capitalista aparece como uma condição da sociedade fabril, trazendo em sua estrutura a lógica contida na relação com o trabalho assalariado, alienado e explorado, a divisão do trabalho e a hegemonia dos meios de 
produção. Assim, a escola se consolida na relação Homo faber e Homo sapiens, portanto, na divisão entre aqueles que são formados para o trabalho via de regra manual e aqueles que o são para a atividade intelectual. Ocorre aqui uma divisão do próprio homem, e a escola pública, a partir de sua organização, conforme Alves (2001), tende a estar mais próxima desse Homo faber, na medida em que esta cultivou, do seu nascimento até o presente momento, o conceito de trabalho capitalista como princípio educativo.

Nessa lógica, a escola é organizada para a formação da força de trabalho, juntamente com a manutenção de sua divisão classista, com o caráter assistencialista e com a alienação social do proletariado. Desse modo, a escola capitalista (pública) é compreendida pela burguesia (mas também por alguns extratos intermediários) apenas como "gasto", que ao possibilitar o acesso a um conhecimento aligeirado corrobora com seus propósitos de manutenção da hegemonia da ideologia burguesa.

Porém, se a lógica da sociedade capitalista industrial impôs à instituição escolar a finalidade primeira de formar indivíduos adequados a esta mesma lógica - à lógica do mercado e da competividade que este encerra, à submissão a uma condição de desigualdade que é imposta a este indivíduo como uma condição de existência "natural" -, a existência da escola deriva da necessidade ditada pelo desenvolvimento social de elevar a educação a um estágio mais elevado, de superar a educação difusa que remete às formas de organização social que prescindia da escrita e de conhecimentos como a matemática, a geometria, a física, a astronomia etc. E, por mais que se argumente que esta instituição, este espaço de educação, constituiu desde sua origem um espaço privilegiado da aristocracia, não the tira o mérito de ser o espaço do conhecimento superior, do conhecimento elaborado que possibilitou à humanidade, mesmo que somente a uma pequena parte dela, romper com o conhecimento limitado que se produz no âmbito do senso comum que se desenvolve no cotidiano alienado, muito frequentemente, eivado de preconceitos a que se encontram limitadas as classes trabalhadoras das sociedades desiguais (e aqui não nos reportamos especificamente ao capitalismo).

A superioridade da escola em relação às outras formas de educação foi compreendida pelos revolucionários franceses e se expressa no Relatório Condorcet apresentado à Assembleia Nacional em nome do Comitê de Instrução Pública, em 1792:

Oferecer a todos os indivíduos da espécie humana os meios (condições) de prover suas necessidades, de assegurar seu bem-estar, de conhecer e de exercer todos os seus direitos, de entender e de cumprir seus deveres.

Assegurar a cada um deles a facilidade de aperfeiçoar seu engenho (habilidade), de se tornar capaz das funções sociais às quais ele tem o direito 
de ser chamado, de desenvolver toda a extensão de talentos (capacidade) que ele recebeu da natureza; e assim estabelecer, entre os cidadãos, uma igualdade de fato, e tornar real a igualdade política reconhecida pela lei:

Esse deve ser o primeiro objetivo de urna instrução nacional e, sob esse ponto de vista, ela é, para o poder público, um dever de justiça (CONDORCET, 2004, p. 234-235).

Em Marx encontramos tomadas de posição sobre a escola que evidenciam o entendimento de que a educação pública estadual constitui uma conquista que necessita ser defendida pelo proletariado por meio da supressão do controle ideológico que a burguesia e o Estado exercem sobre ela. No Manifesto Comunista, de 1848, encontramos uma passagem sobre educação que diz que "[...] os comunistas não inventam o efeito da sociedade sobre a educação; apenas transformam o seu carácter, arrancam a educação à influência da classe dominante" (MARX; ENGELS, 2005, p. 55). Tal formulação poderia ser associada à nova sociedade socialista, não houvesse mais à frente outra passagem com proposição de medidas a serem tomadas nos "países mais avançados" tais como: adoção de um pesado imposto progressivo, abolição do direito de herança - ambas medidas que induzem à ideia de que a propriedade privada ainda não foi abolida -, e a seguinte proposição: "Educação pública e gratuita de todas as crianças; eliminação do trabalho das crianças nas fábricas tal como é praticado hoje. Combinação da educação com a produção material etc.” (MARX; ENGELS, 2005, p. 58)

Em 1875, em sua Crítica do Programa de Gotha, Marx critica uma formulação contida no texto do projeto de unificação dos partidos socialistas alemães numa única agremiação operária que defendia uma "educação popular sob incumbência do Estado" com a seguinte ponderação:

Uma coisa é estabelecer, por uma lei geral, os recursos das escolas públicas, a qualificação do pessoal docente, os currículos etc. e, como ocorre nos Estados Unidos, controlar a execução dessas prescrições legais por meio de inspetores estatais, outra muito diferente é conferir ao Estado o papel de educador do povo! O governo e a Igreja devem antes ser excluídos de qualquer influência sobre a escola (MARX, 2012, p. 37).

Tal ponderação permite apreender que Marx não guardava uma posição negativa em relação à escola pública estatal, mas que, contrariamente, vislumbrava sua utilidade para as massas trabalhadores, e o mesmo podemos dizer de Gramsci (DORE, 2006, p. 340), quando propunha uma escola unitária que teria como ponto de partida

[...] as relações sociais dentro do capitalismo, já que Gramsci não fala em destruir o capitalismo primeiro e somente depois disso cuidar da educação 
dos trabalhadores. Ele não tem uma visão dicotômica da relação entre Estado e sociedade. A escola unitária está no horizonte de um processo de construção que, por ser dialético, é simultaneamente de destruição.

No entendimento de Gramsci, conforme Manasta (2010), tanto a escola quanto a sociedade deveria ser vista a partir de suas contradições, a burguesia instrumentaliza o Estado para controlar a hegemonia intelectual e prática a bem da conservação e reprodução da ordem capitalista. Para ele, na luta pelo socialismo, além da luta pelo poder político, há que se disputar a hegemonia cultural na sociedade, e na escola, por meio de uma permanente luta contra hegemônica, portanto, contra o capitalismo. (MANASTA, 2010).

Embora este não seja nosso objeto, convém notar que o pensamento gramsciano tornou-se um alvo preferencial, um cavalo de batalha mesmo, da direita religiosa e ultraconservadora contra qualquer iniciativa progressista no plano educacional. Segundo Coutinho (2009, p. 42), "a teoria gramsciana da hegemonia tem sido apresentada como uma forma sutil de "lavagem cerebral", voltada para destruir o senso comum e preparar para o triunfo do comunismo". Tal teoria é acusada de ser a mentora intelectual de uma revolução cultural que visaria à destruição da família e dos valores "sagrados" da civilização ocidental cristã.

A disputa no interior da escola, a partir do entendimento de que esta é uma instituição contraditória, possibilita, e pressupõe, o desenvolvimento de uma pedagogia. Nesse sentido, Marx, Engels e Gramsci defenderam a escola do trabalho, não como formadora de mão de obra, mas a partir do entendimento de que o trabalho constitui a atividade vital humana por excelência, aquela da qual decorre todo processo de formação do gênero humano na qualidade ontologicamente definida como ser social. Saviani (2005), por sua vez, fundamenta sua proposição de uma Pedagogia Histórico-Crítica a partir da concepção de formação que integra a tradição marxista e da reivindicação de que o conhecimento historicamente acumulado e socialmente produzido - que expressa o estágio mais avançado de humanidade atingido pela sociedade - constitua a referência principal para elaboração dos programas de ensino das escolas públicas.

A denominação que Dermeval Saviani (2005) deu para a pedagogia, a qual lançou as bases teórico-metodológicas, "Pedagogia Histórico-Crítica", expressa sua oposição à orientação geral predominante na escola brasileira, assim como o entendimento de que as críticas a esta orientação necessitavam e necessitam ainda ser superadas. A palavra "crítica" remete à realidade da escola existente e a palavra "histórico" ao caráter não-histórico e não- 
dialético da crítica à escola capitalista cujas linhas gerais foram expostas no tópico anterior deste artigo.

\section{Considerações finais}

As reais divergências entre os autores aqui utilizados - que convém ponderar, situamse na perspectiva da crítica ao modelo capitalista de escola implementado pela burguesia reforçam a necessidade de se refletir criticamente sobre a escola pública contemporânea e os limites aparentemente intransponíveis que a sociedade capitalista e a ideologia burguesa lhes impõem. A partir de tal reflexão, torna-se possível vislumbrar a possibilidade do desenvolvimento no interior dessa mesma escola de uma alternativa pedagógica que, ao mesmo tempo que critica seu caráter reprodutor da ideologia e das relações sociais capitalistas, instrumentalize a reflexão, por sua vez, dos meios de superação dos limites impostos por este caráter reprodutor.

A partir do entendimento de que a escola é uma organização social que se adéqua ao momento histórico, uma instituição que encerra contradições, é que depreendemos que a escola capitalista, por si só, não será capaz de construir as condições materiais necessárias para um rompimento sobre e com o capital. Nesse sentido, numa perspectiva dialética que entende a contradição existente entre a sociedade capitalista e o desenvolvimento social assim como entre a escola burguesa e a produção social do conhecimento - e que toda pedagogia pressupõe uma determinada concepção de formação do indivíduo, destacam-se os fundamentos da pedagogia histórico-crítica no que tange à concepção de formação humana. Tal concepção se assenta na tese marxista da centralidade da atividade do trabalho na formação do indivíduo enquanto ser social e no entendimento das condições históricas em que se opera o processo de alienação do indivíduo por meio da perda do sentido do próprio trabalho como atividade vital humana.

Pensando-se a educação no âmbito da escola pública, assinalamos a centralidade do papel do professor enquanto agente consciente de formação humana, portanto, como mediador dos processos de ensino e aprendizagem e da sua constituição, assim como a do aluno, como sujeito social e historicamente situado. Para tanto, assinalamos o avanço das contribuições da Pedagogia Histórico-Crítica, a partir da identificação da natureza e especificidade da educação e da priorização dos conhecimentos elaborados nos âmbitos da produção científica, da filosofia e das artes como base para a elaboração, por sua vez, dos programas de ensino e dos currículos escolares. 


\section{REFERÊNCIAS}

ALTHUSSER, L. Aparelhos ideológicos de Estado: nota sobre os aparelhos ideológicos de estado (AIE). 2. ed. Trad. Walter José Evangelista e Maria Laura Viveiros de Castro. Rio de Janeiro: Edições Graal, 1985.

ALTHUSSER, L. Aparelhos ideológicos do Estado. 2. ed. Editora Graal, 1983. p. 15-53.

ALTHUSSER, L. Ideologia e aparelhos ideológicos do Estado. Lisboa: Presença, 1974.

ALVES, G. L. A produção da escola pública contemporânea. Campinas: Autores Associados, 2001.

BOURDIEU, P. A economia das trocas simbólicas: cap. reprodução cultural e reprodução social. São Paulo: Editora Perspectiva, 1974. p. 295-336.

CASSIN, M. Louis Althusser e a sua contribuição para a sociologia da educação. In: BOITO JR., A.; TOLEDO, C. N. (org.). Marxismo e ciências humanas. São Paulo: Xamã, 2003, p. 327-337. Disponível em: https://marxismo21.org/wp-content/uploads/2014/08/LouisAlthusser-e-Sociologia-da_Educacao-M-Cassin.pdf. Acesso em: 28 jun. 2020.

CONDORCET. Marie-Jean-Antoine Nicolas Caritat. Relatório e projeto de decreto sobre a organização geral da instrução pública, apresentado à primeira assembleia nacional em nome do comitê da instrução pública, nos dias 20 e 21 de abril de 1792. Tradução de Maria Auxiliadora Cavazotti. Revista Educação em Questão, Natal, v. 21, n. 7, p. 234-245, set./dez. 2004.

COUTINHO, C. N. A presença de Gramsci no Brasil. Revista em Pauta. Rio de Janeiro: UERJ, n. 22, 2009.

DAYRELL, J. T. A escola como espaço sociocultural. In: DAYRELL, J. T. (org.). Múltiplos olhares sobre educação e cultura. Belo Horizonte: UFMG, 1996. Disponível em: https:/ensinosociologia.milharal.org/files/2010/09/Dayrell-1996-Escola-espa\%C3\%A7osocio-cultural.pdf. Acesso em: 28 jun. 2020.

DERISSO, J. L. O relativismo do pensamento pós-moderno como legitimação para o ensino religioso na escola pública brasileira. 2012. 228 f. Tese (Doutorado em Educação Escolar) - Faculdade de Ciências e Letras, Universidade Estadual Paulista, Araraquara, 2012.

DERISSO, J. L.; DUARTE, R. C. Crítica ao ideário neoliberal na educação: precarização e descaracterização da escola pública paulista. Revista HISTEDBR On-line, v. 17, n. 4, p. 1169-1185, dez. 2017. Disponível em:

https://periodicos.sbu.unicamp.br/ojs/index.php/histedbr/article/view/8651218/17597 Acesso em: 10 fev. 2021.

DORE, R. Gramsci e o debate sobre a escola pública no Brasil. Cad. Cedes, Campinas, vol. 26, n. 70, p. 329-352, set./dez. 2006 Disponível em: https://www.scielo.br/pdf/ccedes/v26n70/ a04v2670.pdf. Acesso em: 11 set. 2020. 
DUARTE, N. Formação do indivíduo, consciência e alienação: o ser humano na psicologia de A. N. Leontiev. Cad. Cedes, Campinas, v. 24, n. 62, p. 44-63, abr. 2004.

FERRARO, J. L. S. Althusser, Educação, Estado e (Re) Produção. Revista Contemporânea de Educação, v. 9, n. 17, jan./jun. 2014. Disponível em: https://revistas.ufrj.br/index.php/rce/ article/view/1712. Acesso em: 28 jun. 2020.

LUKÁCS, G. A decadência ideológica e as condições gerais da pesquisa científica. In: PAULO NETO, J. Lukács. São Paulo: Ática, 1992. (Coleção Grandes Cientistas Sociais).

MANACORDA, M. A. História da Educação: da antiguidade aos nossos dias. Trad. Gaetano Lo Monaco. Rev. de Paolo Nosella. 13. ed. São Paulo: Cortez, 2010.

MÁRKUS, G. Marxismo e antropologia: o conceito de "essência humana" na filosofia de Marx. São Paulo: Expressão Popular, 2015.

MARX, K. Crítica do Programa de Gotha. Seleção, tradução e notas de Rubens Enderle. São Paulo: Boitempo, 2012. (Coleção Marx-Engels). Disponível em: http://www.afoiceeomartelo.com.br/posfsa/Autores/Marx,\%20Karl/Critica\%20do \%20Programa\%20de\%20Gotha.pdf. Acesso em: 09 mar. 2021.

MARX, K.; ENGELS, F. Manifesto comunista. Organização e introdução de Osvaldo Coggiola. 1. ed. 4. reimp. São Paulo: Boitempo, 2005.

MONASTA, A. Antonio Gramsci. Tradução e organização de Paolo Nosella. Coleção Educadores. Brasília: Ministério da Educação / Fundação Joaquim Nabuco, 2010.

NOGUEIRA, C. M. M.; NOGUEIRA, M. A. A sociologia da educação de Pierre Bourdieu: limites e contribuições. Educação \& Sociedade, ano XXIII, n. 78, abr. 2002. Disponível em: https://www.scielo.br/pdf/es/v23n78/a03v2378.pdf. Acesso em: 10 set. 2020.

SÁ, N. P. Aprofundamento das relações capitalistas no interior da escola. Cadernos de pesquisa, São Paulo, 1986. Disponível em:

http://publicacoes.fcc.org.br/ojs/index.php/cp/article/view/1334. Acesso em: 25 jun. 2020.

SAVIANI, D. Escola e Democracia: para além da "teoria da curvatura da vara". Germinal: Marxismo e Educação em Debate, Salvador, v. 5, n. 2, p. 227-239, dez. 2013.

SAVIANI, D. Escola e democracia: teorias da educação, curvatura da vara, onze teses sobre a educação e política. 42. ed. São Paulo: Autores Associados, 2012. (Coleção Polêmicas do Nosso Tempo, v. 5).

SAVIANI, D. Os desafios da educação pública na sociedade de classes. In: ORSO, P. J. (org.). Educação, sociedade de classes e reformas universitárias. Campinas, SP: Autores Associados, 2007.

SAVIANI, D. Pedagogia histórico-crítica: primeiras aproximações. 9. ed. Campinas: Autores Associados, 2005. 
VELLOSO, J. Socialização e trabalho: escola e produção capitalista. Revista em Aberto, Brasília, v. 3, n. 19, mar. 1984. Disponível em:

http://rbep.inep.gov.br/ojs3/index.php/emaberto/article/view/1858. Acesso em: 28 jun. 2020.

\section{Como referenciar este artigo}

LINS, M.; DERISSO, J. L.; PULITA, E. J. Sobre a possibilidade de uma pedagogia crítica para a escola pública contemporânea. Revista Ibero-Americana de Estudos em Educação, Araraquara, v. 16, n. 3, p. 2010-2029, jul./set. 2021. e-ISSN: 1982-5587. DOI: https://doi.org/ 10.21723/riaee.v16i3.15419

Submetido em: 10/12/2020

Revisões requeridas em: 05/01/2021

Aprovado em: 10/02/2021

Publicado em: 01/07/2021 